Journal of Clinical Investigation
Vol. 43, No. 4, 1964

\title{
Micropuncture Study of Potassium Concentration in Proximal Tubule of Dog, Rat, and Necturus *
}

\author{
John F. Watson, $\nmid$ James R. Clapp, and Robert W. Berliner \\ (From the Laboratory of Kidney and Electrolyte Metabolism, National Heart Institute, \\ Bethesda, Md.)
}

A number of investigators (1-9) have recently studied the potassium concentration in the proximal tubule of rat and Necturus. Unfortunately, there are significant differences in the results obtained by different observers. The general conclusion, however, that potassium is reabsorbed against an electrochemical gradient in the proximal tubule of the rat seems justified. Furthermore, if one compares the ratio of the concentration of potassium in tubule fluid to that in plasma ( $\mathrm{TF} / \mathrm{P} \mathrm{K}$ ) to the corresponding ratio for inulin, potassium appears to be extensively reabsorbed from the proximal tubule.

The study reported in this paper was undertaken in an attempt to define the mechanism by which potassium is handled in the proximal tubule of the dog nephron. It was made possible by the development of a sensitive ultramicromethod for the determination of potassium in biological fluids and the adaptation of micropuncture techniques to the study of renal function in $\operatorname{dog}(10)$. The concentrations of inulin and potassium were determined in the same samples of proximal tubule fluid. In separate sets of experiments, proximal transtubular potential differences were also determined. The concentrations of inulin and potassium in tubule fluid were compared with the respective concentrations in plasma in order to evaluate net potassium reabsorption, and the $\mathrm{TF} / \mathrm{P} \mathrm{K}$ ratio was compared with equilibrium ratios calculated from the transtubular potential by the Nernst equation.

The results of this study differ quantitatively, although not qualitatively, from those reported by others using rat and Necturus as experimental

\footnotetext{
* Submitted for publication July 12, 1963; accepted November 26, 1963.

Presented in part at the 55th Annual Meeting of the American Society for Clinical Investigation, April 28, 1963.

$\dagger$ Special Public Health Fellow.
}

animals. To determine whether this difference was related to species differences or to methodology, a limited number of proximal TF/P K ratios were also determined in rats and Necturus.

\section{Methods}

Studies were performed on male and female mongrel dogs weighing from 9 to $15 \mathrm{~kg}$. The dogs were anesthetized by rapid injection of $200 \mathrm{mg}$ of sodium pentothal administered intravenously as a $2.5 \%$ solution in distilled water; small additional doses were administered from time to time to maintain the desired level of anesthesia. The left kidney was exposed through a flank incision, and indwelling catheters were inserted into the ureter of the experimental kidney, the foreleg vein, and the femoral vein. Methods of exposing and supporting the kidney for micropuncture as well as the techniques of tubule fluid collection and identification have previously been reported (10). The samples of tubule fluid were generally 0.03 to $0.05 \mu 1$ in volume and were collected in 5 minutes or less.

In all dog experiments, 15-minute urine collection periods for the determination of inulin and potassium clearances were obtained while tubule fluid samples were being collected. After appropriate priming and sustaining infusions of inulin had been given, 30 minutes was allowed to elapse before collections were begun to insure stable concentrations of inulin in plasma. Venous blood was drawn at the mid-point of each period, and urine was collected through the ureteral catheter. It has previously been demonstrated that the surgical manipulation necessary for tubule fluid collections in the dog does not appreciably alter the function of the experimental kidney when it is compared to its contralateral control (10). If during the course of the experiment the glomerular filtration rate fell by $20 \%$ or more, the results were discarded.

The transtubular potential differences were measured by pyrex glass microelectrodes as described by Ling and Gerard (11). The glass microelectrodes were filled with $3 \mathrm{M} \mathrm{KCl}$ and connected to a $\mathrm{Ag}-\mathrm{AgCl}$ electrode through a lucite chamber filled with $3 \mathrm{M} \mathrm{KCl}$. The lucite chamber was mounted on the head of a De Fonbrune micromanipulator and the $\mathrm{Ag}-\mathrm{AgCl}$ electrode connected to the input of a Cary vibrating-reed electrometer. The reference side of the circuit consisted of a $\mathrm{Ag}-\mathrm{AgCl}$ electrode in contact with a $3 \mathrm{M} \mathrm{KCl}$ bridge placed on the sur- 
face of the kidney. The potentials were recorded on a Sanborn multichannel recorder. Because of respiratory movements in the dog preparation, stable potentials longer than 20 seconds were difficult to obtain. In spite of the short duration, the character of the potential measurement was identical to that seen in more stable preparations such as the rat. Upon entering the tubule there was an abrupt deflection of the recorder styius that stabilized and lasted a variable period of time. Withdrawal of the electrode from the tubule lumen resulted in an abrupt fall of the stylus to within $1 \mathrm{mv}$ of the base line. Rarely, a potential measurement identical in character to the above would remain stable for 40 to 60 seconds. However, the majority of tubule impalements resulted in potential measurements identical in character to the above but lasting less than $10 \mathrm{sec}-$ onds, and it was obvious that when the animal breathed, the tip of the electrode moved within the tubule lumen, resulting in an immediate loss of potential. Various attempts to measure potentials during temporary inhibition of respiration with succinyl choline were unsatisfactory, primarily because, upon cessation of artificial respiration, the kidney immediately lost its turgor and pulsation, and blood flow and tubule fluid flow appeared to diminish. Upon reinstitution of artificial respiration the kidney slowly and progressively returned to its normal size and character. Since repeated attempts to obtain prolonged stable potentials were unsatisfactory, a potential measurement stable for 10 seconds and returning to within $1 \mathrm{mv}$ of the base line on withdrawal of electrode from the tubule was considered satisfactory. No attempt was made to localize the site of the potential measurement along the tubule, since distal tubules have not been located on the surface of the adult dog kidney (10) and since no correlation between site within the proximal tubule and magnitude of potential has been observed in either Necturus (12) or rat (4).

Four groups of dogs were studied: 1) normal nondiuretic, 2) potassium-loaded, 3) potassium-depleted, and 4) normal dogs undergoing mannitol diuresis. Potassium-loaded animals were fed a diet containing $20 \mathrm{~g}$ of $\mathrm{KCl}$ daily for 1 week before the study and infused with a $\mathrm{KCl}$ solution at the rate of $33.5 \mu \mathrm{Eq}$ per minute per $\mathrm{kg}$ throughout the experiment. The potassium-depleted dogs were fed a potassium-free diet and in addition received $5 \mathrm{mg}$ of desoxycorticosterone acetate intramuscularly each day until 2 days before the experiment. The fourth group of dogs was infused with $20 \%$ mannitol at the rate of $3.0 \mathrm{ml}$ per minute throughout the study.

Additional experiments were performed on male and female Sprague-Dawley rats weighing between 200 and $400 \mathrm{~g}$. The rats were maintained on Purina rat chow and were allowed free access to food and water up to the time of the experiment. Each rat was anesthetized with Nembutal ( $3 \mathrm{mg}$ per $100 \mathrm{~g}$ body weight), a tracheotomy was performed, and an indwelling catheter was inserted into the jugular vein. The left kidney was exposed through a left flank incision and suspended on a glass kidney holder. Tubule fluid samples were collected and analyzed for potassium from both normal nondiuretic animals and rats receiving $20 \%$ mannitol at the rate of $0.1 \mathrm{ml}$ per minute. Blood was obtained at the end of the experiment from the abdominal aorta. In rats undergoing a mannitol diuresis, urine flows as high as $0.13 \mathrm{ml}$ per minute were obtained through a polyethylene catheter inserted into the ureter of the experimental kidney.

Micropuncture samples from Bowman's capsule and proximal tubules of Necturus were also collected. Experiments were performed in the months of May and June on animals that had been kept at $4^{\circ} \mathrm{C}$ in amphibian Ringer's solution for 1 to 8 weeks. The Necturi were anesthetized with $1 \%$ tricaine in amphibian Ringer's solution, and the mesonephros was exposed by a midline abdominal incision. The head of the animal was immersed in oxygenated Ringer's solution to which a small amount of the original anesthetic solution was added. The experimental kidney was bathed in Ringer's solution while tubule fluid samples were being collected. Care was taken to avoid contamination of the sample with the bathing solution. Blood was obtained at the end of the experiment from the abdominal vein and anticoagulated with heparin. The puncture site within the proximal tubule was determined by filling the entire nephron with nigrosine and grossly estimating the location within the proximal tubule from which the sample was obtained.

The tubule fluid potassium concentrations were measured on an ultramicro filter photometer developed for the determination of alkali metals in biological fluids. The method uses as its energy source for cation excitation a helium plasma produced by discharging a radio frequency through a helium atmosphere. The potassium emission in turn is picked up by a red-sensitive photomultiplier at wave lengths of 766 to $769 \mathrm{~m} \mu$ and the peak response recorded on a peak recording meter.

Preliminary investigations established that sodium concentrations up to 40 mmoles per $\mathrm{L}$ depressed the potassium emission in a progressive manner; however, above 40 mmoles per $\mathrm{L}$ the depression was constant. Likewise, increasing concentrations of bicarbonate, phosphate, and sulphate depressed the emission; these effects could be swamped by 1 mmole per $\mathrm{L}\left(\mathrm{NH}_{4}\right)_{2} \mathrm{HPO}_{4}$. In addition, 0.3 mmole per $\mathrm{L} \mathrm{CsCl}$ was used in an attempt to enhance the potassium emission.

Potassium determinations were always done within 1 to 2 hours after the collection of the samples. 0.005 $\mu 1$ of tubular fluid was withdrawn into a constant bore capillary micropipette by capillary action, transferred under oil, and delivered into $0.1 \mu \mathrm{l}$ of diluting fluid containing 0.3 mmole per $\mathrm{L} \mathrm{CsCl}, 50$ mmoles per $\mathrm{L} \mathrm{NaCl}$, and 1 mmole per $\mathrm{L}\left(\mathrm{NH}_{4}\right)_{2} \mathrm{HPO}_{4} .0 .01 \mu \mathrm{l}$ of this final $1: 21$ dilution was then placed on an iridium wire having a diameter of 0.004 inches. The wire with the sample was then placed in a chamber flushed with helium and the cation excited as described above. All samples and standards were handled identically, and each unknown was bracketed between two nearest standards. A de- 
TABLE I

Comparison of micro- and macro-potassium methods on plasma ultrafiltrate; Necturus glomerular fluid to plasma ratios*

\begin{tabular}{|c|c|c|c|c|c|}
\hline \multicolumn{3}{|c|}{ Plasma ultrafiltrates } & \multicolumn{3}{|c|}{ Necturus } \\
\hline Micro & Macro & Micro: Macro & $\begin{array}{c}\text { Glomerular fluid } \\
\text { Micro }\end{array}$ & $\begin{array}{l}\text { Plasma } \\
\text { Macro }\end{array}$ & $G F: P$ \\
\hline$m E q / L$ & $m E q / L$ & & $m E q / L$ & $m E q / L$ & \\
\hline 4.79 & 4.28 & 1.12 & 3.98 & 3.67 & 1.08 \\
\hline 3.37 & 3.56 & 0.95 & 3.85 & & 1.05 \\
\hline 3.91 & 4.29 & 0.91 & 3.78 & & 1.03 \\
\hline 4.42 & 4.08 & 1.08 & 3.08 & & 0.84 \\
\hline 3.17 & 3.40 & 0.93 & 3.00 & & 0.82 \\
\hline 3.08 & 3.53 & 0.87 & & & \\
\hline 3.90 & 4.17 & 0.94 & 2.49 & 2.26 & 1.10 \\
\hline 3.70 & 3.69 & 1.00 & 2.60 & & 1.15 \\
\hline 3.57 & 3.49 & 1.02 & 3.43 & & 1.52 \\
\hline 1.93 & 2.20 & 0.88 & 2.54 & & 1.12 \\
\hline 3.23 & 3.40 & 0.95 & 3.17 & & 1.40 \\
\hline 3.75 & 4.05 & 0.93 & 2.31 & & 1.02 \\
\hline 4.00 & 4.09 & 0.98 & & & \\
\hline 3.42 & 3.60 & 0.95 & 1.54 & 1.86 & 0.83 \\
\hline 3.75 & 3.73 & 1.00 & 1.66 & & 0.89 \\
\hline \multirow[t]{2}{*}{3.11} & 3.35 & 0.93 & 1.63 & & 0.88 \\
\hline & & & 1.77 & & 0.95 \\
\hline \multirow[t]{4}{*}{ Mean } & & 0.97 & 1.25 & 1.20 & 1.04 \\
\hline & & & 1.48 & & 1.23 \\
\hline & & & 1.25 & & 1.04 \\
\hline & & & Mean & & 1.06 \\
\hline
\end{tabular}

* See text.

tailed description of the method is in preparation for publication.

Standard curves based upon from $5 \times 10^{-13}$ moles to $5 \times 10^{-12}$ moles of potassium differed from day to day and were not ideally linear. However, they did not deviate far from linearity, and the slope was steep enough to allow accurate interpolation between standards. Nine separate determinations on one plasma ultrafiltrate, prepared by the method of Toribara, Terepka, and Dewey (13), gave a standard deviation of $\pm 6 \%$. Sixteen samples of plasma ultrafiltrate were analyzed for potassium by the micromethod and compared with the results as determined on a Baird flame photometer. Also 18 samples collected from Bowman's space were obtained from four Necturi, analyzed for potassium by the micromethod, and compared with the plasma concentration as determined on the Baird flame photometer. The results are shown in Table I. The potassium concentration in plasma ultrafiltrates determined by the micromethod averaged $97 \%$ (range, 87 to $112 \%$ ) of that found using the macromethod. The glomerular samples averaged $106 \%$ of the respective plasma values, with a range from 82 to $152 \%$.

Inulin in tubule fluid was determined on $0.02 \mu 1$ of sample by the microanthrone method of Hilger, Klümper, and Ullrich (14). Inulin in plasma and urine was determined by the macroanthrone method of Führ, Kaczmarczyk, and Krüttgen (15). Potassium in plasma and urine was determined with a Baird flame photometer, model DB-5.

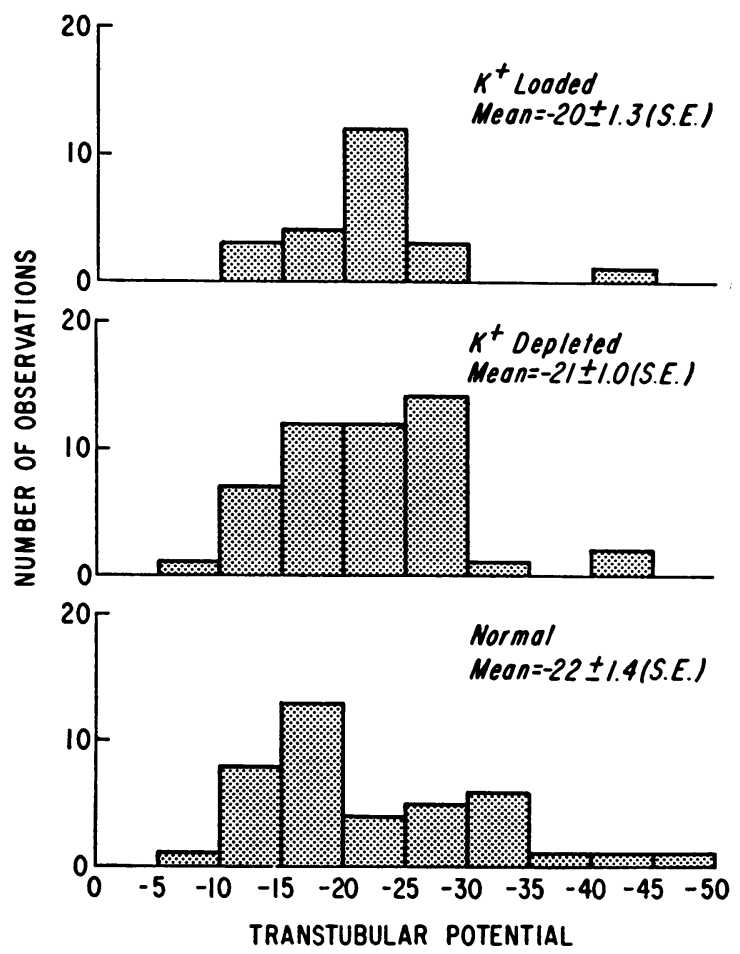

Fig. 1. Proximal transtubular potential differENCES. Values in millivolts referred to extracellular fluid taken as zero. 


\section{Results}

Proximal transtubular potential differences $\left(E_{T}\right)$

The distributions of measurements of the $E_{\mathbf{T}}$ across the proximal tubule in the normal nondiuretic dog, and in potassium-depleted and potassium-loaded animals are shown in Figure 1. There was a scatter of potentials, ranging from 8 to 45 $\mathrm{mv}$, with a mean $\mathrm{E}_{\mathrm{T}}$ of $22 \mathrm{mv}$, lumen negative to extracellular fluid, in the normal dog. There were no significant differences between normal and potassium-loaded or -depleted animals. Transtubular potentials obtained from one dog during $20 \%$ mannitol infusion were of the same order of mag- nitude; however, because of excessive motion of the kidney, stable potentials were impossible to obtain, and a definitive evaluation of the $E_{T}$ during mannitol infusion cannot be made.

\section{Potassium in proximal tubule fluid}

1) Normal nondiuretic dogs. The TF/P K ratios obtained from four normal dogs are illustrated in Figure 2. The mean plasma potassium concentration for each dog is shown in the upper right hand corner of the figure, and the TF/P K ratios obtained for the corresponding experiment are designated by identical symbols. Also illustrated is the fraction of the filtered potassium
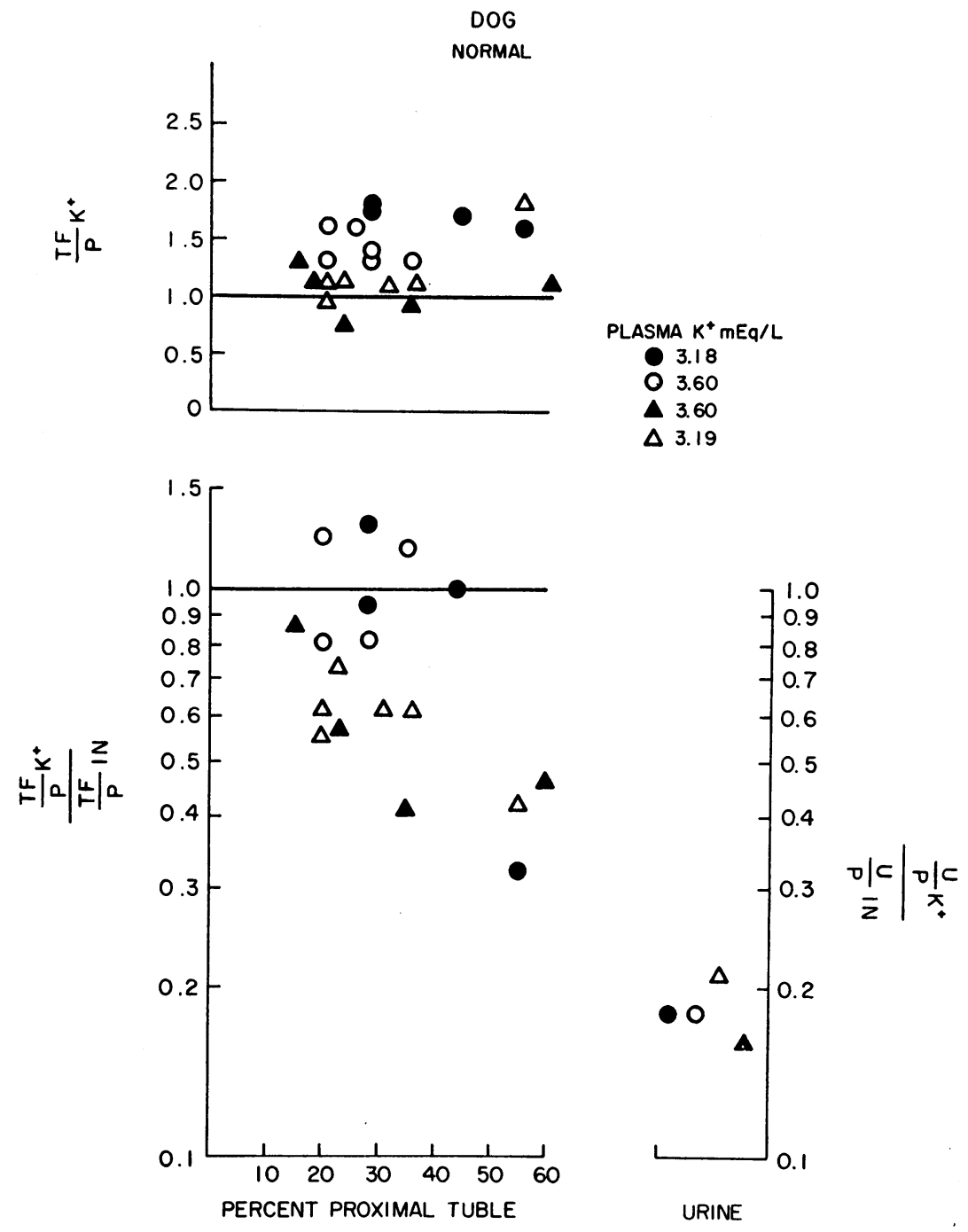

Fig. 2. $\mathrm{K}$ IN PROXIMAL TUBULE FLUID; NORMAL NONDIURETIC DOGS. TF= tubule fluid; $\mathrm{P}=$ plasma; In $=$ inulin. 


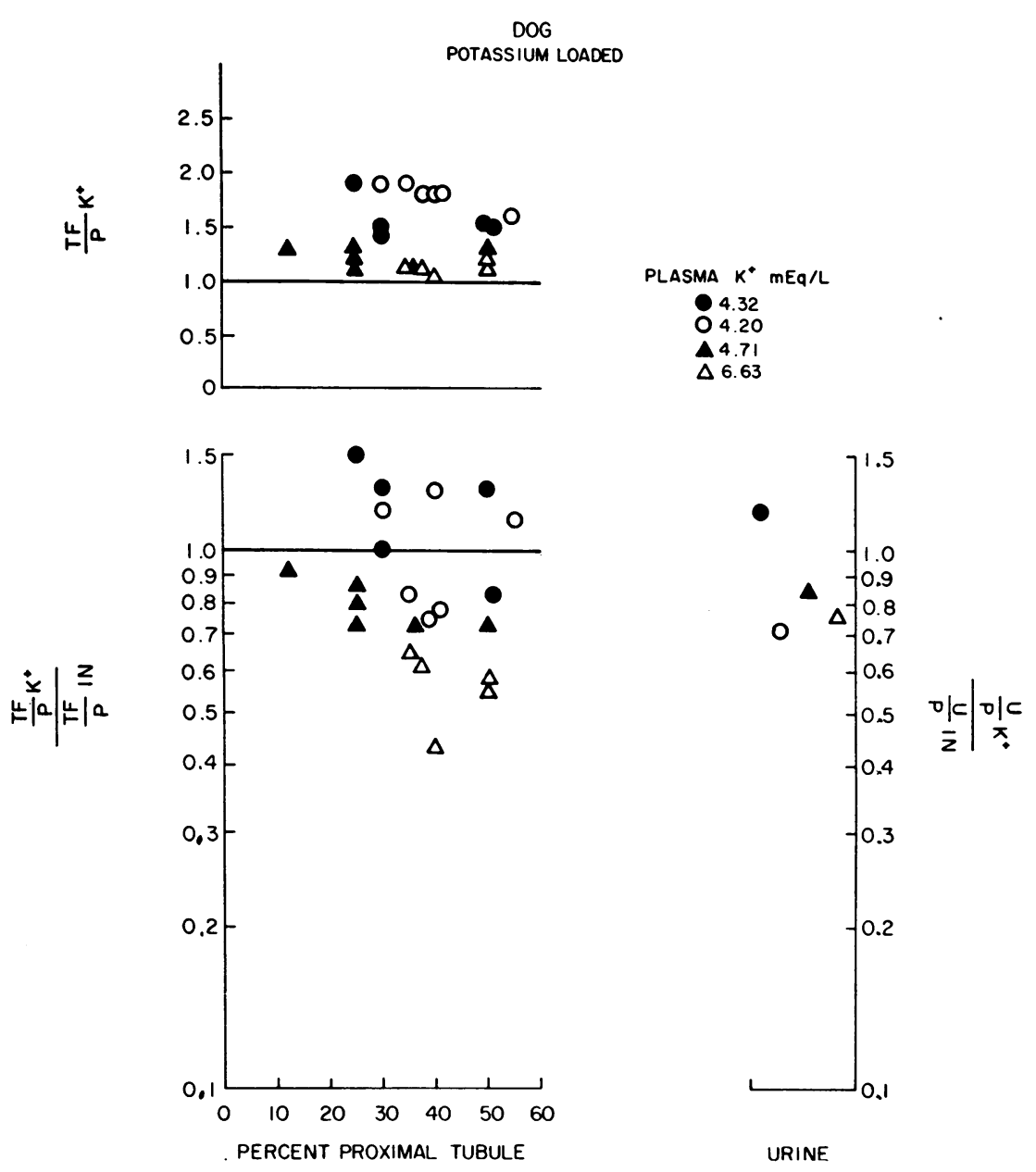

Fig. 3. $\mathrm{K}$ in PRoximal tUbUle fluid; K-LOAdEd DOGS.

remaining at various points along the proximal tubule as determined by dividing the $\mathrm{TF} / \mathrm{P} \mathrm{K}$ ratio by $\mathrm{TF} / \mathrm{P}$ inulin ratio. The mean values for the potassium-inulin clearance ratios $[(\mathrm{U} / \mathrm{P} \mathrm{K}) /$ (U/P In)] for each dog are shown on the lower right.

The mean $\mathrm{TF} / \mathrm{P} \mathrm{K}$ ratio was $1.32(\mathrm{SD} \pm 0.29)$, and there was no relationship between the ratio and position within the tubule. The fraction of filtered potassium remaining within the proximal tubule, however, became progressively smaller, reflecting the increasing inulin $\mathrm{TF} / \mathrm{P}$ ratios. The mean fraction of the filtered potassium remaining in the middle third of the proximal tubule was $0.63(\mathrm{SD} \pm 0.31)$.

2) Potassium-loaded dogs. Figure 3 shows results obtained from four potassium-loaded dogs. Potassium excretion was much greater than in normal dogs; however, the $\mathrm{TF} / \mathrm{P} \mathrm{K}$ ratio did not differ significantly from that in the normal animals, the mean in the potassium-loaded dogs being $1.43(\mathrm{SD} \pm 0.30)$. Net potassium reabsorption was also demonstrated throughout the proximal tubule. The mean fraction of filtered potassium remaining in the middle third of the proximal tubule, $0.86(\mathrm{SD} \pm 0.29)$, although greater than in the normal dogs, was not significantly different.

3) Potassium-depleted dogs. In these studies, Figure 4, potassium excretion was at a minimum, and serum potassium was depressed to the range of 2.3 to $3.2 \mathrm{mEq}$ per L. The mean TF/P K ratio in the proximal tubule of $1.05(\mathrm{SD} \pm 0.14$ ) was significantly lower $(p<0.001)$ than in the normal and potassium-loaded dogs. The fraction of the filtered potassium remaining in the proxi- 
mal tubule in potassium depletion, $0.60(\mathrm{SD} \pm$ 0.17 ) in the middle third, was not different from that in normal animals.

4) Mannitol diuresis in normal dogs. The $\mathrm{TF} / \mathrm{P} \mathrm{K}$ ratio was fairly consistently less and the mean significantly less than 1.0 when normal dogs were infused with 20\% mannitol (Figure 5). Here the mean TF/P $\mathrm{K}$ ratio of 0.90 (SD \pm $0.18)$ was significantly less $(p<0.001)$ than that observed in the three previous sets of experiments. The mean fraction of the filtered potassium remaining in the middle third of the proximal tubule during mannitol diuresis, $0.58(\mathrm{SD} \pm 0.14$ ), did not differ significantly from that in the normal animals. The data identified by closed triangles are not included in the calculations of either the mean $\mathrm{TF} / \mathrm{P} \mathrm{K}$ ratio or $(\mathrm{TF} / \mathrm{P} \mathrm{K}$ ratio) $/(\mathrm{TF} / \mathrm{P}$ In ratio) because the glomerular fil- tration rate throughout the experiment was abnormally low. However, they are included in the figure to demonstrate further that $\mathrm{TF} / \mathrm{P} \mathrm{K}$ ratios considerably less than 1.0 can be observed in the proximal tubule.

5) Normal nondiuretic rats. The TF/P K ratios from six nondiuretic rats are shown in Figure 6. As in the dog, there was no relationship between position within the tubule and the TF/P K ratio. The mean $\mathrm{TF} / \mathrm{P} \mathrm{K}$ ratio of 1.34 ( $\mathrm{SD} \pm$ 0.25 ) was essentially the same as that found in normal nondiuretic dogs.

6) Mannitol diuresis in normal rats. Figure 7 illustrates the TF/P K ratios obtained from three rats undergoing mannitol diuresis. Although the majority of ratios was not less than 1.0 , as was the case in dogs during mannitol infusion, the mean $\mathrm{TF} / \mathrm{P} \mathrm{K}$ ratio of 1.09 ( $\mathrm{SD} \pm 0.15)$ was sig-
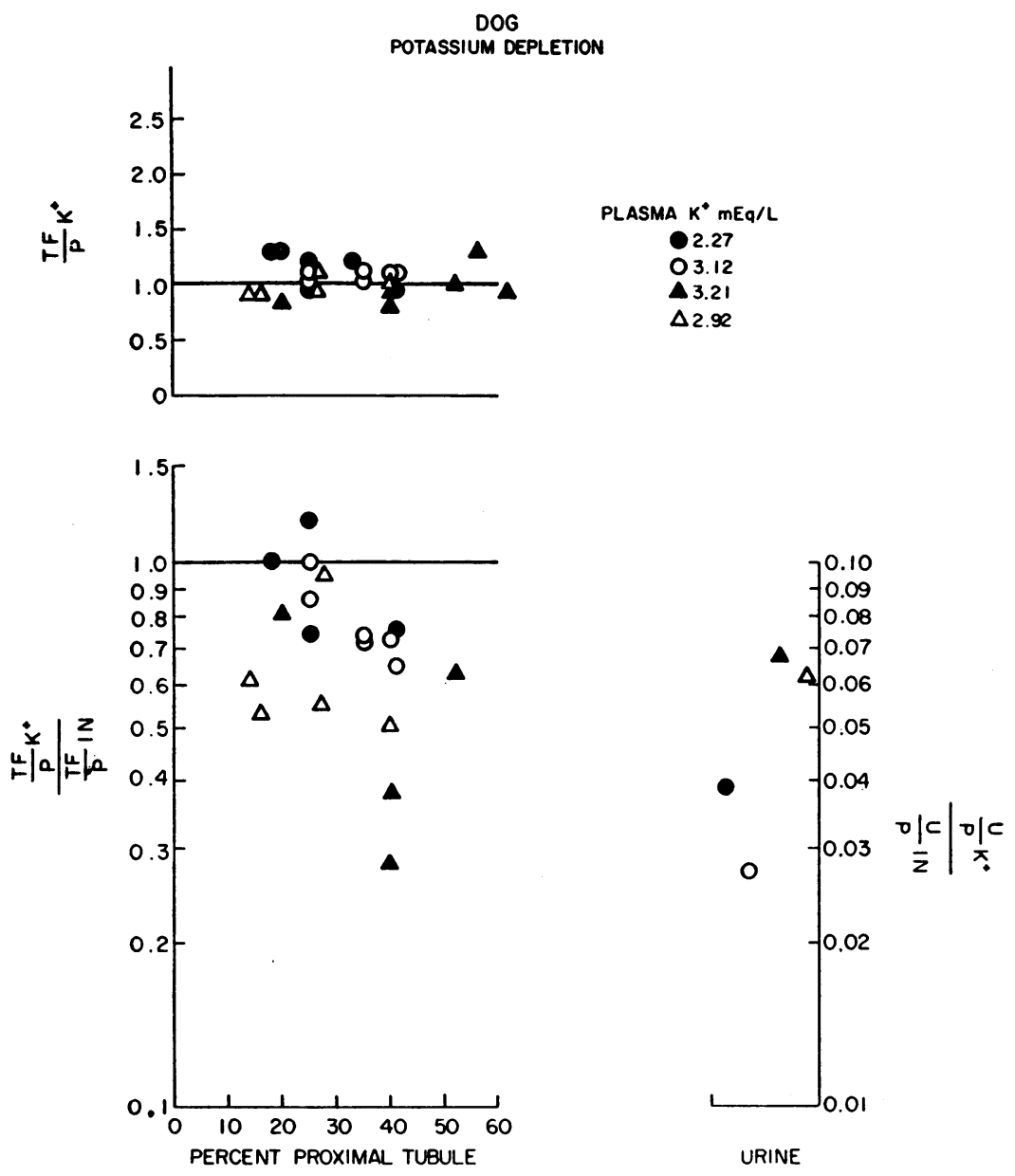

Fig. 4. $\mathrm{K}$ in proximal tubule fluid; K-Depleted dogs. 
DOG

MANNITOL OIURESIS

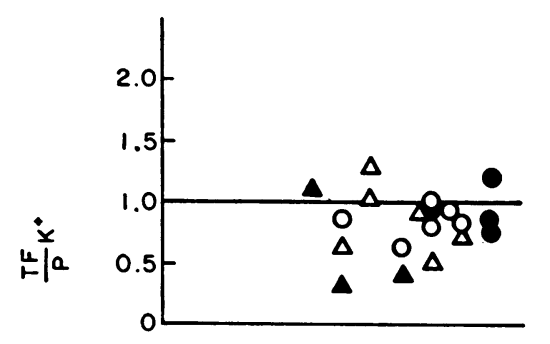

PLASMA $K^{+} m E q / L$

03.84

03.27

$\Delta \mathbf{\Delta} \mathbf{3 . 7 7}$
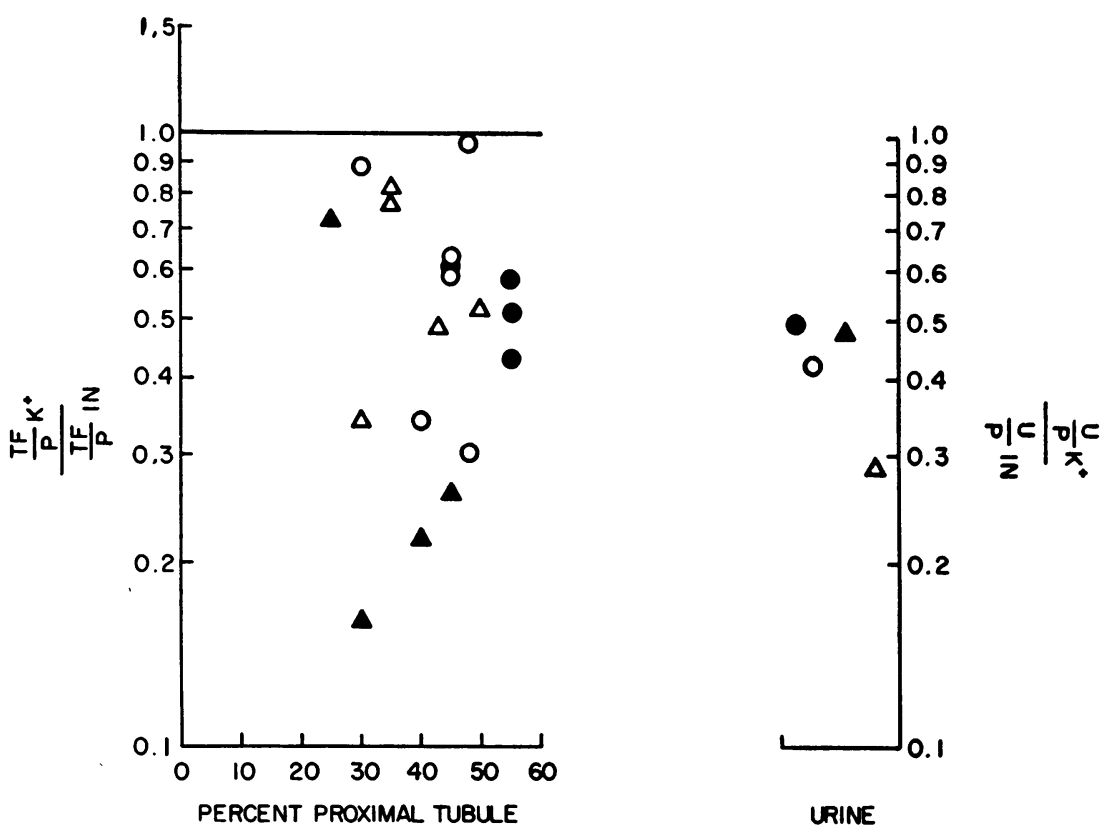

Fig. 5. K IN PRoXimal tUbUle FlUid; MANNitol diURESis in NORMal DOGS.

nificantly lower $(p<0.01)$ than that obtained in normal nondiuretic rats.

7) Necturus. Fifteen TF/P K ratios obtained from four Necturi are shown in Figure 8. Al-

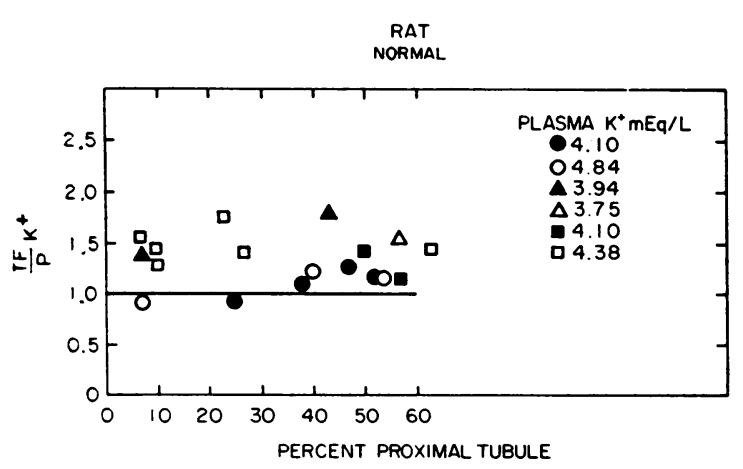

Fig. 6. K IN PROXIMAL TUbUle FLUID; NORMAL NONDIURETIC RATS. though there was considerable scatter throughout the proximal tubule, the mean $\mathrm{TF} / \mathrm{P} \mathrm{K}$ ratio of 1.76 was higher than that found in either normal dogs or rats. Furthermore, there were eight ra-

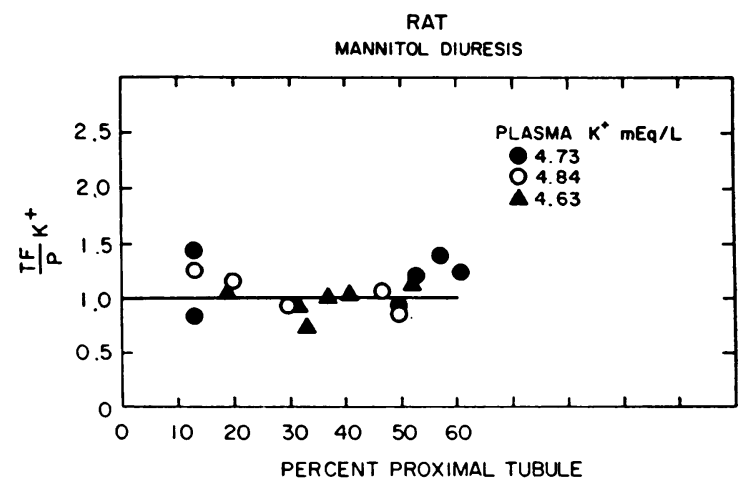

Fig. 7. K in proximal tUbUle fluid; ManNitol diURESIS IN NORMAL RATS. 


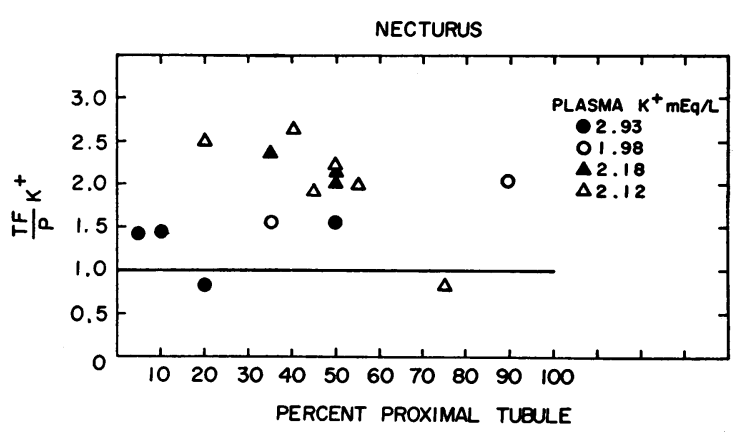

Fig. 8. $\mathrm{K}$ in PRoximal tUbUle fluid; Necturus.

tios which were 2.0 or greater. Ratios as high as 2.0 were not observed in either the dog or rat experiments.

\section{Discussion}

A number of publications have been concerned with the transtubular potential difference generated across the proximal tubular epithelium of the Necturus (12) and rat (4, 16-19). All of the studies demonstrate a scatter of potentials ranging from 5 to $50 \mathrm{mv}$, lumen negative to extracellular fluid, with an average potential approximating $20 \mathrm{mv}$ in the normal animal. In this study, the potentials observed in the proximal tubule of the dog nephron are of the same magnitude as those found in previous studies of other species. Furthermore, conditions of low and high net potassium excretion do not alter the proximal transtubular potentials in the dog. Although a definitive evaluation of the proximal transtubular potential during mannitol diuresis could not be made for reasons previously mentioned, the lumen was always negative to extracellular fluid.

The Nernst equation, $E=-61.5 \log \mathrm{K}_{\mathrm{t}} / \mathrm{K}_{\mathrm{p}}$, defines the relationship of the transtubular potential to the distribution of potassium between tubule lumen $\left(\mathrm{K}_{\mathrm{t}}{ }^{+}\right)$and extracellular fluid $\left(\mathrm{K}_{\mathrm{p}}{ }^{+}\right)$ to be expected at thermodynamic equilibrium. If the $\mathrm{TF} / \mathrm{P} \mathrm{K}$ ratio is less than that required for equilibrium at the measured transtubular potential, an electrochemical gradient exists opposing the movement of potassium out of the tubule lumen. For a transtubular potential difference of $22 \mathrm{mv}$, lumen negative to extracellular fluid, the Nernst equation would require a TF/P $\mathrm{K}$ ratio of 2.3 if potassium were distributed passively. The mean $\mathrm{TF} / \mathrm{P} \mathrm{K}$ ratios in all groups of dogs studied were well below 2.3, and the highest single ratio observed was 1.9. The Nernst equation defines the relationship between electrical and chemical gradients only at equilibrium, and deviations from the expected values imply only that equilibrium does not exist. However, deviation of the TF/P K ratio in the direction observed, coupled with the demonstration of net potassium reabsorption from the tubule, constitutes evidence for active transport.

Solvent drag, i.e., the force exerted upon a solute by the flow of solvent through a membrane (20), can result in net transport of an ion across a membrane against its electrochemical gradient. Therefore, concentration ratios less than that predicted for passive distribution by the Nernst equation could be observed and transport not be mediated by an active process. However, ratios less than 1.0 cannot result from solvent drag alone, since this would imply relatively more solute than solvent movement across the membrane. Since $\mathrm{TF} / \mathrm{P} \mathrm{K}$ ratios less than 1.0 have been demonstrated in dogs undergoing a mannitol diuresis along with net reabsorption of potassium against an electrochemical gradient, it seems reasonable to conclude that potassium reabsorption from the proximal tubule of the dog nephron is mediated by an active transport process.

It seems unwarranted to add to the proposed models for potassium transport, since the observations do not allow any conclusion concerning intracellular events, and the development of such a model would necessitate extrapolation from other species. Nevertheless, the data are consistent with a potassium pump located on the luminal surface of the tubule cell, which transports potassium out of the tubule lumen against its electrochemical gradient, as previously proposed by a number of investigators $(21,4,8)$.

Berliner (22) has reviewed the evidence which suggests that potassium is not only reabsorbed and secreted by the mammalian nephron, but that all or nearly all of the filtered potassium is reabsorbed at a point in the tubule proximal to the more distal secretory site responsible for the potassium excreted in the urine. Proof of this hypothesis will depend on the demonstration of complete reabsorption of potassium in the proximal tubule, loop of Henle, or early distal tubule.

The data presented in this paper demonstrate 
that reabsorption of potassium is progressive along the proximal tubule. Although the percentage of filtered potassium reabsorbed in the middle third of the proximal tubule ranges from $37 \%$ in normal animals to $14 \%$ in potassiumloaded dogs, the difference is not significant. Furthermore, because of the scatter and paucity of points in the middle third of the tubule, without further data it would be hazardous to extrapolate beyond the middle third in regard to the extent that the proximal tubule contributes to the total amount of potassium reabsorbed by the nephron. It does appear, however, that the adjustments in potassium transport which result in the wide range of potassium excretion occur largely in more distal portions of the nephron.

The impetus to resolve the question of proximal tubular reabsorption of potassium has resulted in the recent appearance in the literature of a number of micropuncture studies dealing with the $\mathrm{TF} / \mathrm{P} \mathrm{K}$ ratio in rat and Necturus (1-9). Wirz and Bott (1) were the first to study the potassium concentration in the proximal tubule of rats. They observed in rats undergoing a mild osmotic diuresis $\mathrm{TF} / \mathrm{P} \mathrm{K}$ ratios in the proximal tubule ranging from 0.26 to 1.14 , with a mean of 0.69 . In contrast, Litchfield and Bott (3) recently reported ratios that remained close to 1.0 in nondiuretic rats. Bloomer, Rector, and Seldin (4) demonstrated $\mathrm{TF} / \mathrm{P} \mathrm{K}$ ratios in normal nondiuretic rats ranging from 0.70 to 1.20 , with a mean of 0.92. Out of 25 samples only 6 had TF/P K ratios greater than 1.10. Similar $\mathrm{TF} / \mathrm{P} \mathrm{K}$ ratios in normal diuretic rats have recently been reported by Malnic and Giebisch (6). Marsh, Ullrich, and Rumrich (8), utilizing standard flame photometry, and Khuri, Flanigan, and Oken (7), using cation-sensitive glass electrodes, reported mean $\mathrm{TF} / \mathrm{P} \mathrm{K}$ ratios of 0.79 and 0.73 , respectively, in nondiuretic rats. The discrepancies in the results obtained by different investigators preclude a definitive statement concerning the fraction of the filtered potassium reabsorbed in the proximal tubule of the normal rat. Nevertheless, the general conclusion that potassium is reabsorbed against an electrochemical gradient seems justified.

In Necturus, however, the discrepancies in results do not allow such a conclusion, since Bott (2) observed a mean proximal $\mathrm{TF} / \mathrm{P} \mathrm{K}$ ratio of 1.0 (a result identical to that which she obtained in rats by the same method), while Oken and Solomon (5) observed ratios of 1.6 by flame photometry and Khuri and co-workers (9) from the same laboratory observed a mean ratio of 1.8 by the use of potassium-sensitive glass electrodes. The latter studies may imply passive distribution of potassium across the Necturus proximal tubule epithelium.

Since the proximal $\mathrm{TF} / \mathrm{P} \mathrm{K}$ ratio observed in the normal nondiuretic dogs was at variance with all the studies mentioned above, proximal TF/P K ratios were also determined in normal nondiuretic rats, rats undergoing a mannitol diuresis, and Necturus. The mean $\mathrm{TF} / \mathrm{P} \mathrm{K}$ ratio of 1.3 in normal rats is essentially the same as that observed in normal dogs, suggesting that the discrepancy between the results obtained in dogs in this study and in rats by others $(1,3,4,6-8)$ is not due to a species difference. Furthermore, normal rats undergoing a mannitol diuresis had significantly lower $\mathrm{TF} / \mathrm{P} \mathrm{K}$ ratios, with a mean of 1.09. Although quantitatively the ratios are higher than those previously reported, they support the concept of active transport of potassium out of the proximal tubule lumen of the rat.

It is difficult to reconcile the wide variety of results that have been reported; however, a few points deserve comment. The most striking difference among the various studies has been the utilization of a variety of methods for the determination of potassium in ultramicrovolumes of biological fluid. The methods have ranged from chemical to various modifications of the flame photometer, to the use of cation-sensitive glass electrodes, and finally to a filter photometer not utilizing a flame but a helium plasma. Unfortunately, no two investigators have used identical methods, and each method was a developmental project carried out specificially by the investigator for the purpose for which it was used. Furthermore, the physiological condition of the experimental animal deserves mention. Since in the rat it is difficult to be certain of the physiological status of the experimental preparation, differences in the physiologic state of the animal along with errors involved in methodology may have led to the discrepancies in results.

The mean proximal $\mathrm{TF} / \mathrm{P} \mathrm{K}$ ratio of $1.8 \mathrm{ob}-$ served in Necturus is in good agreement with the published data of Oken and Solomon (5) and 
Khuri and co-workers (9), but distinctly different from that reported by Bott (2). The TF/P K ratios were distinctly higher in Necturus than in rats or dogs, with eight ratios 2.0 or higher. Since no simultaneous measurements were made of inulin in tubule fluid, and transtubular potentials were not measured, these studies do not bear in any definitive way on the nature of potassium handling in the proximal tubule of Necturus.

\section{Summary}

Inulin and potassium concentrations were determined in the same samples of proximal tubule fluid obtained from four groups of dogs : normal, potassium-loaded, potassium-depleted, and normal dogs undergoing a mannitol diuresis. Transtubular potentials were also determined in identically prepared animals. The mean proximal transtubular potential of $22 \mathrm{mv}$, lumen negative to extracellular fluid, observed in four normal dogs was not significantly different from that observed in potassium-loaded or potassium-depleted dogs. The mean ratio of potassium concentration in tubule fluid to the potassium concentration in plasma was 1.32 in normal dogs, 1.43 in potassium-loaded dogs, 1.05 in potassium-depleted dogs, and 0.90 during mannitol diuresis in dogs; all are lower than the equilibrium ratio calculated from the Nernst equation for a transtubular potential of 22 mv. Analysis of single samples of tubule fluid for both inulin and potassium demonstrated net potassium reabsorption in the proximal tubule in all experiments. The demonstration of net potassium reabsorption against an electrochemical gradient constitutes evidence for active transport of potassium out of the proximal tubule lumen of the dog nephron. The absence of major differences in the extent of potassium reabsorption in the proximal tubule in dogs excreting widely varying amounts of potassium indicates that the adjustments which determine the rate of excretion occur largely in more distal portions of the nephron.

In normal nondiuretic rats and rats undergoing mannitol diuresis, the mean ratios of potassium concentration in tubule fluid to potassium concentration in plasma were 1.30 and 1.09 , respectively. A mean concentration ratio of 1.76 was found in the proximal tubule of Necturus.

\section{Acknowledgment}

The authors gratefully acknowledge the able technical assistance of Miss Nordica Green.

\section{References}

1. Wirz, H., and P. A. Bott. Potassium and reducing substances in proximal tubule fluid of the rat kidney. Proc. Soc. exp. Biol. (N. Y.) 1954, 87, 405.

2. Bott, P. A. Micropuncture study of renal excretion of water, $\mathrm{K}, \mathrm{Na}$, and $\mathrm{Cl}$ in Necturus. Amer. J. Physiol. 1962, 203, 662.

3. Litchfield, J. B., and P. A. Bott. Micropuncture study of renal excretion of water, $\mathrm{K}, \mathrm{Na}$, and $\mathrm{Cl}$ in the rat. Amer. J. Physiol. 1962, 203, 667.

4. Bloomer, H. A., F. C. Rector, Jr., and D. W. Seldin. The mechanism of potassium reabsorption in the proximal tubule of the rat. J. clin. Invest. 1963, 42, 277.

5. Oken, D. E., and A. K. Solomon. Single proximal tubules of Necturus kidney. VI: Nature of potassium transport. Amer. J. Physiol. 1963, 204, 377.

6. Malnic, G., and G. Giebisch. Micropuncture study of renal potassium excretion in the rat. Fed. Proc. 1963, 22, 631.

7. Khuri, R. N., W. J. Flanigan, and D. E. Oken. Micropuncture study of the potassium concentration in proximal tubule using glass electrodes. Clin. Res. 1963, 11, 245.

8. Marsh, D. J., K. J. Ullrich, and G. Rumrich. Micropuncture analysis of the behavior of potassium ions in rat renal cortical tubules. Pflügers Arch. ges. Physiol. 1963, 277, 107.

9. Khuri, R. N., D. A. Goldstein, D. L. Maude, C. Edmonds, and A. K. Solomon. Single proximal tubules of Necturus kidney. VIII: $\mathrm{Na}$ and $\mathrm{K}$ determinations by glass electrodes. Amer. J. Physiol. 1963, 204, 743.

10. Clapp, J. R., J. F. Watson, and R. W. Berliner. Osmolality, bicarbonate concentration, and water reabsorption in the proximal tubule of the dog nephron. Amer. J. Physiol. 1963, 205, 273.

11. Ling, G., and R. W. Gerard. The normal membrane potential of frog sartorius fibers. J. cell. comp. Physiol. 1949, 34, 383.

12. Giebisch, G. Electrical potential measurements on single nephrons of necturus. J. cell. comp. Physiol. 1958, 51, 221.

13. Toribara, T. Y., A. R. Terepka, and P. A. Dewey. The ultrafilterable calcium of human serum. I. Ultrafiltration methods and normal values. J. clin. Invest. 1957, 36, 738.

14. Hilger, H. H., J. D. Klümper, and K. J. Ullrich. Wasserrückresorption und Ionentransport durch die Sammelrohrzellen der Saugetierniere. Pflügers Arch. ges. Physiol. 1958, 267, 218.

15. Fuhr, J., J. Kaczmarczyk, and C. D. Krüttgen. Eine einfache colorimetrische Methode zur Inulinbestim- 
mung für Nieren-Clearance-Untersuchungen be : Stoffwechselgesunden und Diabetikern. Klin. Wschr. 1955, 33, 729.

16. Solomon, S. Transtubular potential differences of rat kidney. J. cell. comp. Physiol. 1957, 49, 351.

17. Clapp, J. R., F. C. Rector, Jr., and D. W. Seldin. Effect of unreabsorbed anions on proximal and distal transtubular potentials in rats. Amer. J. Physiol. 1962, 202, 781.

18. Bank, N. Relationship between electrical and hydrogen ion gradients across rat proximal tubule. Amer. J. Physiol. 1962, 203, 577.

19. Kashgarian, M., H. Stöckle, C. W. Gottschalk, and K. J. Ullrich. Transtubular electrochemical po- tentials of sodium and chloride in proximal and distal renal tubules of rats during antidiuresis and water diuresis (diabetes insipidus). Pflügers Arch. ges. Physiol. 1963, 277, 89.

20. Ussing, H. H., and B. Andersen. The relation between solvent drag and active transport of ions. Proc. 3rd Int. Congr. Biochem. 1955, 434.

21. Giebisch, G. Measurements of electrical potentials and ion fluxes on single renal tubules. Circulation 1960, 21, 879.

22. Berliner, R. W. Renal mechanisms for potassium excretion in The Harvey Lectures. New York, Academic Press, 1959-60, series 55, p. 141. 